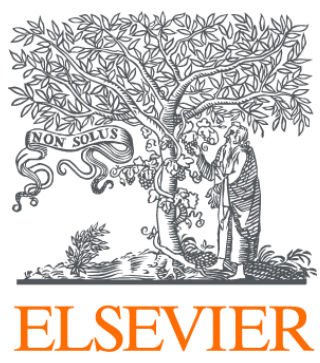

Since January 2020 Elsevier has created a COVID-19 resource centre with free information in English and Mandarin on the novel coronavirus COVID-

19. The COVID-19 resource centre is hosted on Elsevier Connect, the company's public news and information website.

Elsevier hereby grants permission to make all its COVID-19-related research that is available on the COVID-19 resource centre - including this research content - immediately available in PubMed Central and other publicly funded repositories, such as the WHO COVID database with rights for unrestricted research re-use and analyses in any form or by any means with acknowledgement of the original source. These permissions are granted for free by Elsevier for as long as the COVID-19 resource centre remains active. 


\title{
Middle East respiratory syndrome
}

\author{
Ziad A Memish, Stanley Perlman, Maria D Van Kerkhove, Alimuddin Zumla
}

The Middle East respiratory syndrome coronavirus (MERS-CoV) is a lethal zoonotic pathogen that was first identified in humans in Saudi Arabia and Jordan in 2012. Intermittent sporadic cases, community clusters, and nosocomial outbreaks of MERS-CoV continue to occur. Between April 2012 and December 2019, 2499 laboratory-confirmed cases of MERS-CoV infection, including 858 deaths (34.3\% mortality) were reported from 27 countries to WHO, the majority of which were reported by Saudi Arabia (2106 cases, 780 deaths). Large outbreaks of human-to-human transmission have occurred, the largest in Riyadh and Jeddah in 2014 and in South Korea in 2015. MERS-CoV remains a high-threat pathogen identified by WHO as a priority pathogen because it causes severe disease that has a high mortality rate, epidemic potential, and no medical countermeasures. This Seminar provides an update on the current knowledge and perspectives on MERS epidemiology, virology, mode of transmission, pathogenesis, diagnosis, clinical features, management, infection control, development of new therapeutics and vaccines, and highlights unanswered questions and priorities for research, improved management, and prevention.

\section{Introduction}

During the past 17 years three lethal zoonotic diseases of humans caused by novel coronaviruses, severe acute repiratory syndrome (SARS) in November, 2002, ${ }^{1}$ Middle East respiratory syndrome (MERS) in April, 2012, and more recently coronavirus disease (COVID-19) in December, 2019. ${ }^{3}$ All three causative coronaviruses, respectively, SARS-CoV, MERS-CoV, and SARS-related coronavirus-2 (SARS-CoV-2) have focused the attention of global public health authorities and are listed in the WHO Blueprint list for priority pathogens ${ }^{4}$ because of their pandemic potential, threat to global health security, and the absence of any effective treatments.

SARS-CoV was first identified in humans in Guangdong, China, in November, 2002 and subsequently spread rapidly worldwide to 29 countries, resulting in 8098 human SARS cases with 774 deaths $\left(9 \cdot 6 \%\right.$ mortality) ${ }^{1,5}$ The SARS epidemic ended abruptly in July, 2003, ${ }^{1}$ and no human cases of SARS have been detected over the past 15 years. MERS-CoV was first identified as causing human disease when it was isolated from a lung sample of an adult patient who was admitted at a hospital in Jeddah, Saudi Arabia, with severe pneumonia and died of multiorgan failure. ${ }^{6}$ A retrospective study then linked MERS-CoV to a hospital outbreak in April, 2012, in Jordan.? MERS-CoV is considered a zoonotic pathogen, with MERS-CoV-infected dromedary camels being the animal source of infection to humans. ${ }^{8,9}$

Unlike SARS-CoV, which was contained within a year of emerging, MERS-CoV continues to circulate and cause human disease with intermittent sporadic cases, community clusters, and nosocomial outbreaks in the Middle East with considerable risk of spreading globally., ${ }^{2,10}$ Several outbreaks of human-to-human MERS-CoV transmission have occurred, the largest outside the Middle East occurring in South Korea in 2015..$^{11,12}$ This outbreak was associated with substantial morbidity and mortality, as well as having substantial economic, social, and health security effects. ${ }^{12}$

SARS-CoV-2 (initially named 2019-nCoV) was detected in December 2019 after sequencing of clinical samples from a cluster of patients in Wuhan, China who developed pneumonia of unknown cause. ${ }^{13}$ This outbreak is rapidly evolving and as of March 3, 2020 there have been 88948 laboratory confirmed cases of COVID-19, with 3043 deaths (3.4\% mortality). Outside China, there have been 8774 cases reported from 64 countries with 128 deaths. $^{3}$

This Seminar reviews current knowledge and provides an update on MERS-CoV epidemiology, virology, mode of

\section{Search strategy and selection criteria}

We searched publications in the English language literature on PubMed and Google Scholar (dates we used to refine our search: Sept 1, 2012, to Dec 31, 2019). We used the search terms "Middle East Respiratory Syndrome" OR "MERS-CoV" OR "MERS" in combination with the terms "Coronavirus", OR "Middle East", OR "Epidemiology", "Aetiology", "Dromedaries", "Camels", "Bats", OR "Transmission", OR "Virology" OR "Pathogenesis", "Clinical features" OR "Infection control", "Diagnostic tests", OR "Diagnosis" OR "Treatment", OR "Management", OR "drugs", "Therapies", OR "Prevention" OR "Vaccines" OR "Nosocomial" OR "Hospital". We also searched websites of global and national public health agencies such as WHO, WHO-Regional Office for the Eastern Mediterranean, UN Food and Agriculture Organization, US Centers for Disease Control and Prevention (CDC), Public Health England (UK), World Organisation for Animal Health, European Centre for Disease Prevention and Control (ECDC), and the Saudi Ministry of Health Middle East respiratory syndrome (MERS) portal. We reviewed publications on MERS from WHO, CDC, ECDC, Center for Infectious Disease Research and Policy (University of Minnesota, USA), and ProMED (Program for Monitoring Emerging Diseases) websites. We focused our review on publications published in the past 36 months to update the Lancet Seminar on MERS published in September, 2015. We also selected reference lists and substantive reviews of articles identified by this search strategy that we judged relevant to provide readers with additional details and more references than this Seminar can accommodate.
Lancet 2020; 395: 1063-77

Published Online March 4, 2020 https://doi.org/10.1016/ S0140-6736(19)33221-0

\section{College of Medicine,} Alfaisal University, Riyadh, Saudi Arabia (Prof Z A Memish FRCP), Research Center, King Saud Medical City Ministry of Health, Riyadh, Saudi Arabia (Prof Z A Memish); Hubert Department of Global Health, Rollins School of Public Health, Emory University, Atlanta, GA, USA (Prof Z A Memish); Department of Microbiology and Immunology, and Department of Pediatrics, University of lowa, lowa City, IA, USA (Prof S Perlman PhD); Infectious Hazards Management, Health Emergencies Programme, World Health Organization, Geneva, Switzerland (M D Van Kerkhove PhD); Department of Infection Division of Infection and Immunity, Centre for Clinical Microbiology, University College London, London, UK (Prof Sir A Zumla FRCP); and National Institute for Health Research Biomedical Research Centre, University College London Hospitals, London, UK (Prof Sir A Zumla)

Correspondence to: Prof Sir Alimuddin Zumla, Department of Infection, Division of Infection and Immunity, Centre for Clinical Microbiology, University College London, London, NW3 OPE, UK a.zumla@ucl.ac.uk 
transmission, pathogenesis, diagnosis, clinical features, management, infection control, and development of new therapeutics and vaccines, and also highlights unanswered questions and priorities for research, improved management, and prevention.

\section{Virology}

MERS-CoV, SARS-CoV, and SARS-CoV-2, are members of the Coronaviridae family of the order Nidovirales. Other human coronaviruses generally cause mild respiratory infections (eg, HCoV-229E, HCoV-NL63, HCoV-OC43, and HCoV-HKU1). MERS-CoV, like SARS-CoV and SARS-CoV-2, can cause highly lethal disease in humans. MERS-CoV is a large single-strand positive-sense RNA virus (figure 1)..$^{14-18}$ The $30-31 \mathrm{~kb}$ coronavirus genome encodes a large number of proteins, which might confer versatility in adapting to new environments and enhance cross-species transmission. MERS-CoV has four structural proteins: spike (S) protein, envelope (E)protein, membrane $(\mathrm{M})$ protein, and nucleocapsid $(\mathrm{N})$ protein.

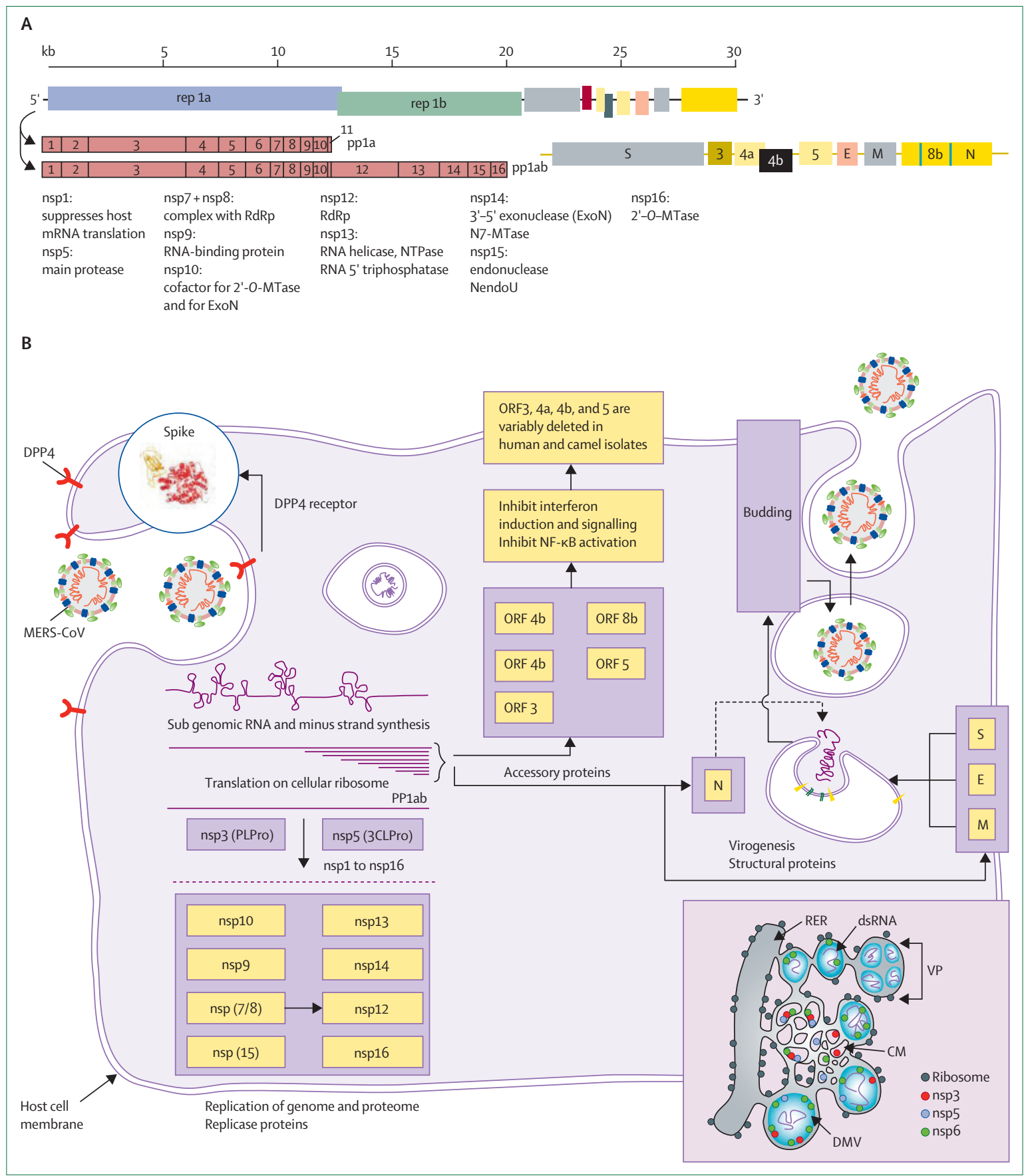


The $\mathrm{S}$ protein is a type I transmembrane glycoprotein located as a trimer on the virus surface and consists of S1 and S2 subunits. It has crucial roles in binding, fusion, and entry into host cells. The S1 subunit has a receptor binding domain that binds to the host cellular receptor dipeptidyl peptidase 4 (DPP4). The S2 subunit has two regions, heptad repeats 1 and 2 (HR1 and HR2), which rearrange to form a six-helix bundle to enable membrane fusion. The $\mathrm{E}$ and $\mathrm{M}$ proteins are present in the viral membranes and are required for viral assembly, budding, and intracellular trafficking.

MERS-CoV enters host cells via binding of its $S$ protein to the host cell DPP4 receptor (figure 1; appendix pp 2-3). ${ }^{15,17}$ DPP4 is less abundant in the nasal cavity and epithelial cells of the upper airways but is highly expressed on the epithelial cells of the distal airways and type I and II pneumocytes in the lung alveoli, non-ciliated bronchial epithelial cells, endothelial cells, and some haemopoietic cells. ${ }^{15}$ DPP4 is also widely expressed on the epithelial cells of several other organs and tissues such as the kidneys, intestine, liver, thymus, and bone marrow - thus widespread dissemination of MERS-CoV could occur in the body. The structures of the S protein of MERS-CoV and other coronaviruses have been determined using cryo-electron microscopy ${ }^{16,17}$ and provide

Figure 1: MERS-CoV structure, genome organisation, and replication MERS-CoV encodes a large replicase-transcriptase polyprotein (rep1A and rep1B), which is processed into 16 non-structural proteins (nsp). These proteins are required for the formation of the replicase-transcription complex, for cleavage of the polyprotein, and for immune evasion. Structural proteins (spike [S], envelope [E], membrane [M], and nucleocapsid [N]) and accessory proteins (ORFs $3,4 a, 4 b, 5,8 b$ ) are encoded in the end third of the 3 ' end of the genome of the genome. MERS-CoV binds to its cellular receptor DPP4 via the $S$ protein, which is processed by host proteases to expose a fusion peptide. The viral genome is then released into the cytoplasm, where it is translated on host ribosomes into rep1A and rep1B proteins. The polyprotein is cleaved by two viral-encoded proteases, encoded by nsp3 and nsp5. Proteins involved in genome and subgenome replication and transcription include nsp12 (the RNA-dependent RNA polymerase [RdRP]) and two associated proteins, nsp7 and nsp8. ${ }^{127} \mathrm{Nsp} 13$ (a helicase), nsp14 (which encodes an N7 methyltransferase and ExoN, a protein required for genome fidelity), and nsp16 (a 2'-O methyltransferase) are also necessary for optimal genomic and subgenomic RNA synthesis. MERS-CoV transcription involves the synthesis of subgenomic RNAs, which encode the structural and accessory proteins located at the $3^{\prime}$ end of the genome. Subgenomic and genomic RNAs are co-terminal, sharing the same $5^{\prime}$ leader and 3 ' sequences. Subgenomic RNAs code for structural and accessory proteins (ORF3,4a, 4b, 5, and 8b). ORF8b is encoded within the $\mathrm{N}$ gene (marked with purple lines). These accessory proteins are believed to have immunoevasive properties, but are not essential for replication, and are variably deleted in human and camel virus isolates. ${ }^{128-130} \mathrm{Genomic}$ replication occurs on membrane structures such as double membrane vesicles (DMVs), convoluted membranes (CM), and vesicle packets (VP), which are merged $D_{M V} V^{131}$ that have been formed from the rough endoplasmic reticulum (RER) by the combined action of nsp3, nsp4, and nsp6 (lower right). After synthesis on replicase-transcription complexes, RNA is encapsidated by the $\mathrm{N}$ protein and transported to the ERGIC (endoplasmic reticulum-Golgi compartment), where budding into membranes containing the $S, E$, and $M$ proteins occurs before release from the cell. 3 CLPro=chymotrypsin-like protease. ExoN=exonuclease. $\mathrm{MERS}-\mathrm{CoV}=$ Middle East respiratory syndrome coronavirus. $\mathrm{MTase}=$ methyltransferase. NendoU=nidoviral uridylate-specific endoribonuclease. NF- $\mathrm{kB}=$ nuclear factor $\mathrm{k}$-light-chain-enhancer of activated $\mathrm{B}$ cells. NTPase=nucleoside-triphosphatase. $\mathrm{pp} 1 \mathrm{a}=$ polyprotein $1 \mathrm{a}$. PLPro=papainlike protease. the basis for rational design of protective antibodies and other therapeutics.

\section{Epidemiology}

A primary MERS-CoV infection is defined by WHO as a laboratory-confirmed MERS-CoV infection that has no direct epidemiological link to a human MERS-CoV infection, and was acquired outside of a health-care facility presumably from direct or indirect contact with the reservoir host-dromedary camels. ${ }^{19}$

A secondary MERS-CoV infection is defined by WHO as a laboratory-confirmed MERS-CoV infection with a direct epidemiological link to an individual with confirmed or probable MERS-CoV infection. ${ }^{19}$

\section{Geographical distribution}

Laboratory-confirmed MERS-CoV human infections ${ }^{19}$ are reported to WHO as a requirement under the International Health Regulations (2005). The geographical distribution of countries reporting laboratory-confirmed human MERS cases and the numbers reported over time are shown in figures 2 and 3. Between April, 2012 and end of December, 2019, 2499 laboratory-confirmed human cases of MERS-CoV infection, including 858 deaths (34.3\% mortality) were reported from 27 countries in all continents (figure 2) to WHO, the majority of which were reported by Saudi Arabia (2106 cases, 780 deaths).

\section{Sources of infection}

The origin of all primary human MERS-CoV infections remains unknown. Dromedary camels are a host reservoir species for the MERS-CoV (appendix pp 3-5). ${ }^{20-23}$ Humans can acquire MERS-CoV through direct or indirect contact with infected dromedary camels or infected patients ${ }^{19-30}$ (figure 4A). However not all cases infected in the community report contact with dromedary camels (appendix p 4-5). The transmission of MERS-CoV from dromedary camels to humans is now well documented in the Arabian Peninsula, ${ }^{23-25}$ but the extent to which this transmission is occurring in countries outside the Arabian Peninsula requires definition. Experimental infections have shown that infected dromedaries shed MERS-CoV from their nasal secretions with minimal signs of illness, which is limited to rhinorrhoea. ${ }^{27-29}$ Full-genome phylogenetic analysis indicates that evolution of diverse MERS-CoV lineages in camels have caused human infections, perpetuating a low barrier for interspecies transmission. 21,29,30 However, African MERS-CoV lineages in camels imported into Saudi Arabia have not established themselves in camels in Saudi Arabia, ${ }^{9,30}$ indicating potential differences in transmission dynamics and selection pressure. Analysis of population dynamics shows that Arabian viruses can maintain endemicity without introduction of additional lineages. ${ }^{9,30}$ WHO is supporting molecular and serological studies at the dromedary-human interface in several countries in 


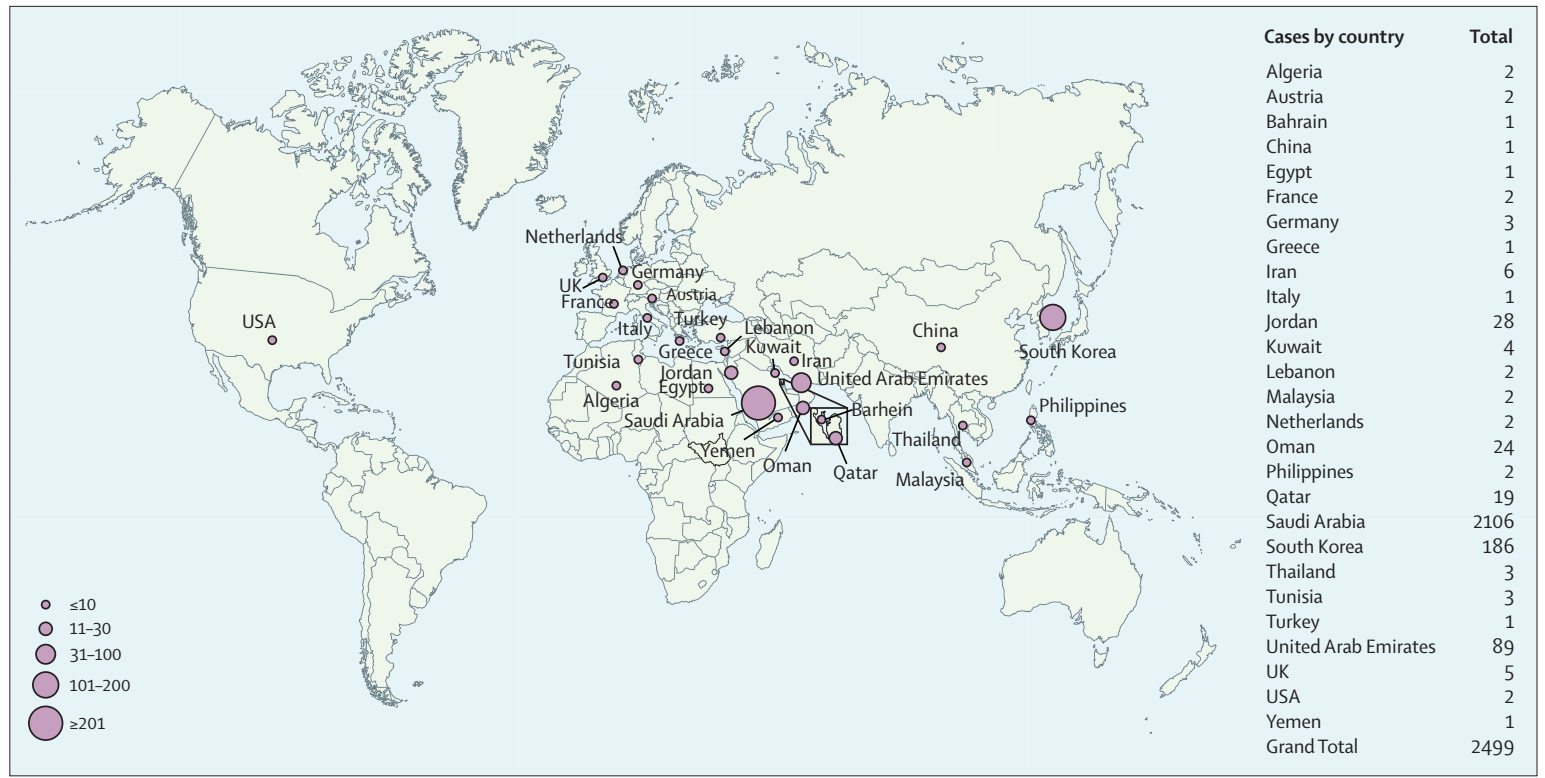

Figure 2: Geographical distribution of reported human infections of MERS-CoV

Cases reported up to and including Dec 31, 2019. MERS-CoV=Middle East respiratory syndrome coronavirus. Reproduced from Dr Mamunur R Malik, WHO Regional Office for the Eastern Mediterranean.

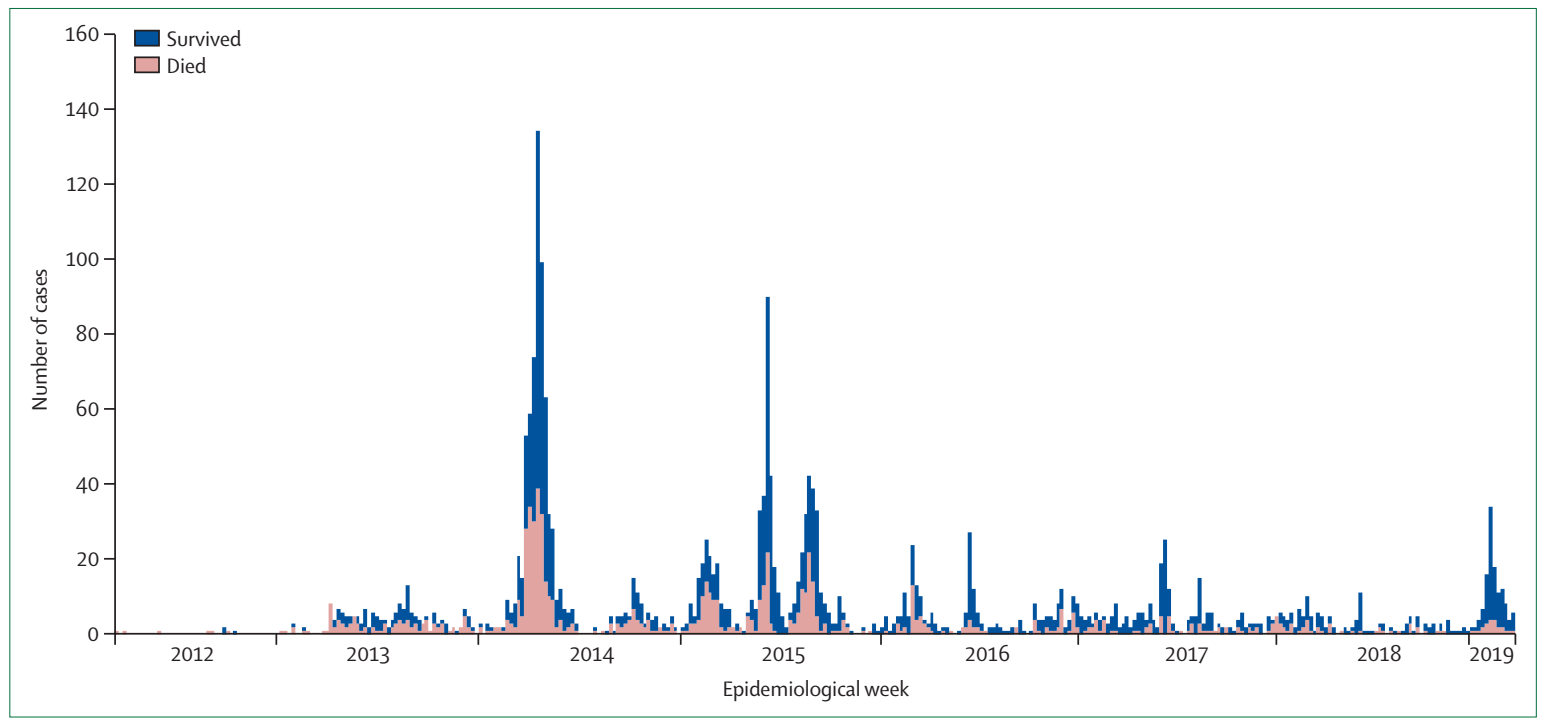

Figure 3: Global MERS reported to WHO by week, 2012-19

Reproduced from WHO website, by permission of Dr Mamunur R Malik, WHO Regional Office for the Eastern Mediterranean. MERS=Middle East respiratory syndrome.

Africa and south Asia. ${ }^{31}$ The phylogenetic relationship of complete genomes of MERS-CoV strains obtained from camels and humans has been published. ${ }^{32}$

\section{Epidemiological patterns of human cases}

The epidemiological patterns of MERS-CoV in humans have remained consistent since MERS-CoV was first identified in 2012. ${ }^{2}$ Primary cases often report direct or indirect contact with dromedary camels and present across a wide clinical spectrum from mild to severe fulminant disease. Individuals with severe primary
MERS-CoV infections are often older than 65 years with comorbidities, and symptoms can present late. Individuals with mild primary MERS-CoV infections are often missed by current surveillance systems since they usually do not present to health-care facilities.

Secondary cases have resulted from human-to-human transmission among close contacts. To date, secondary transmission has occasionally occurred between close contacts of individuals with laboratory-confirmed MERS-CoV in household settings. ${ }^{33,34}$ However, secondary transmission in health-care facilities has repeatedly 


\begin{tabular}{|c|c|c|c|}
\hline A Sources of MERS-CoV & B Probable MERS-CoV routes of entry, circulation, and organ involvement & C Clinical, imaging, and & tory features \\
\hline $\begin{array}{l}\text { Animal and environmental sources } \\
\text { MERS-CoV-infected camels } \\
\text { Camel nasal secretions } \\
\text { Camel excreta (urine, saliva and } \\
\text { faeces) } \\
\text { Camelid birth products (amniotic } \\
\text { fluid, fetal membranes and placenta) } \\
\text { Camel food products (milk, meat) } \\
\text { Other unknown? } \\
\text { Human sources } \\
\text { Symptomatic and subclinical } \\
\text { MERS-positive individuals in: } \\
\text { The community } \\
\text { Family households } \\
\text { Family compounds } \\
\text { Hostels } \\
\text { Health-care facilities and hospitals } \\
\text { Camel farms } \\
\text { Up to } 25 \% \text { report direct or indirect } \\
\text { contact with camels and approximately } \\
50 \% \text { are the result of human-to-human } \\
\text { transmission }\end{array}$ & $\begin{array}{l}\text { MERS-CoV host cell DPP4 receptor found in: } \\
\text { broncial epithelium, lung parenchyma, interstitium (endothelial cells), } \\
\text { kidneys, intestines, liver, thymus, haemopoetic cells (leukocytes, } \\
\text { macrophages, dendritic cells, mononuclear lymphoid cells) }\end{array}$ & $\begin{array}{l}\text { Presenting symptoms } \\
\text { General } \\
\text { Fever }\left(>38^{\circ} \mathrm{C}\right) \\
\text { Chills or rigours } \\
\text { Lethargy } \\
\text { Anorexia } \\
\text { Malaise, lethargy } \\
\text { Myalgia } \\
\text { Body aches } \\
\text { CNS } \\
\text { Headache } \\
\text { Confusion } \\
\text { Upper respiratory tract } \\
\text { Runny nose } \\
\text { Sneezing } \\
\text { Sore or tickly throat } \\
\text { Lower respiratory tract } \\
\text { Cough (dry or productive } \\
\text { with sputum) } \\
\text { Shortness of breath } \\
\text { Chest pain } \\
\text { Haemoptysis } \\
\text { Gastrointestinal tract } \\
\text { Decreased appetite } \\
\text { Nausea } \\
\text { Vomiting } \\
\text { Diarrhoea } \\
\text { Abdominal pain } \\
\text { Abdominal discomfort }\end{array}$ & $\begin{array}{l}\text { Incubation period } \\
\text { Mean: } 5 \cdot 2 \text { days } \\
\text { (95\% CI 1.9-14.7) } \\
\text { Range 2-14 days } \\
\text { Sex distribution } \\
\text { Males } 64 \% \text {, females } 36 \% \\
\text { Abnormal investigations } \\
\text { Imaging: chest x-ray and CT changes } \\
\text { Leucopenia } \\
\text { Lymphopenia } \\
\text { Thrombocytopenia } \\
\text { Elevated LDH } \\
\text { Elevated ALT } \\
\text { Elevated AST } \\
\text { Complications } \\
\text { Severe acute respiratory syndrome } \\
\text { Respiratory failure } \\
\text { Liver failure } \\
\text { Renal failure } \\
\text { Multiorgan failure } \\
\text { Septic shock } \\
\text { Factors associated with increased mortality } \\
\text { Comorbidities: } \\
\text { Diabetes } \\
\text { Chronic lung disease (COPD, asthma) } \\
\text { Chronic kidney disease } \\
\text { Chronic liver disease } \\
\text { Chronic heart disease } \\
\text { Malignancies } \\
\text { Immunosuppressive drugs } \\
\text { Age }>65 \text { years } \\
\text { Presence of pleural effusion } \\
\text { Low serum albumin } \\
\text { Case fatality rate } \\
\text { Overall (global): } 36.0 \% \\
\text { Saudi arabia: } 41.8 \% \text { (22\%-69\%) } \\
\text { South korea: } 20 \cdot 4 \%(14 \cdot 5-47 \% \text { ) }\end{array}$ \\
\hline
\end{tabular}

Figure 4: Epidemiological, clinical, and laboratory features of MERS

ALT=alanine aminotransferase. $A S T=$ asparate aminotransferase. MERS-CoV=Middle East respiratory syndrome coronavirus.

occurred in several countries and has, on occasion, resulted in large outbreaks (appendix p 5)-such as Jeddah, Saudi Arabia (2014), Seoul, South Korea (2015), and Riyadh, Saudi Arabia (2015, 2016, and 2018). In health-care settings, human-to-human transmission occurs between patients, between patients and healthcare workers, and from patients to visitors. ${ }^{21,33}$ Approximately half of the MERS-CoV cases reported to $\mathrm{WHO}^{2}$ to date have resulted from human-to-human transmission in health-care facilities. ${ }^{21,33}$

\section{Risk factors and transmission}

Known risk factors for MERS-CoV acquisition, transmission, and outbreaks are noted (panel 1). MERS patient data reported to WHO includes information on exposures and known risk factors during the 14 days before symptom onset, or during the 14 days before laboratory confirmation was reported (in the case of asymptomatic infection). Exposure data include travel history to MERS-CoV endemic countries, direct or indirect contact with dromedary camels or their products, contact with humans with MERS-CoV infection, and visits to health-care facilities containing patients infected with MERS-CoV are risk factors for acquiring MERS-CoV infection (appendix pp 4-5)..$^{2,24,25,31-45}$ MERS-CoV has been detected in camel products (eg, raw milk, meat, blood, urine, or birth products); however, genomic studies to definitively show transmission from these products to humans have not yet been done. Human primary intestinal epithelial cells, small intestine explants, and the intestinal tract are highly susceptible to MERS-CoV and can sustain viral replication. After infection of mice transgenic for the expression of the host DPP4 receptor, histological examination showed MERS-CoV enteric infection in all inoculated mice with progression to infection of the lung tissues, indicating the development of sequential respiratory infection. ${ }^{39}$

Transmission via contact with contaminated hospital environments is possible during outbreaks, although genomic studies providing an evidence base are lacking. Since environmental contamination is a potential source of infection, it is prudent to take precautionary infection control measures.

\section{Nosocomial transmission}

Health-care-associated outbreaks of MERS-CoV affecting inpatients, health-care workers, and visitors are characteristic of MERS (panel 2) and account for approximately 
Panel 1: Risk factors for MERS-CoV infection, transmission, and outbreaks ${ }^{21,34,38,132-138}$

\section{Community risk factors}

- Indirect or direct contact with MERS-CoV-infected camels, camel nasal secretions, milk, urine, faeces, meat, or birthing products

- Travel to the Middle East and contact with camels or attendance at a health facility

- Exposure to, or contact with, patients with MERS-CoV in the community, or at healthcare facilities

- Underlying chronic medical conditions

Nosocomial risk factors for human-to-human transmission and outbreak amplification

- Late diagnosis of MERS-CoV infection

- Lack of awareness in health-care workers of the possibility of MERS in patients with a fever

- Overcrowded or contaminated health-care facilities, especially emergency departments, dialysis units, and crowded inpatient wards

- Exposure of hospital staff or other patients to symptomatic patients with MERS

- Delayed implementation of infection control measures

- Poor compliance with MERS-specific infection control guidelines (hand hygiene, droplet and contact precautions, environmental cleaning)

- Poor compliance with appropriate personal protective equipment when assessing patients with febrile respiratory illness

- Aerosol-generating procedures or invasive procedures in patients with MERS (eg, nebulisers, resuscitation, intubation, and ventilation)

- Lack of proper isolation room facilities

- Distance between patient beds of less than $1 \mathrm{~m}$

- Friends and family members staying as caregivers in overcrowded health-care facilities

MERS=Middle East respiratory syndrome. MERS-CoV=Middle East respiratory syndrome coronavirus
16 health-care facilities and $80 \%$ of transmission events were attributed to five superspreading events. ${ }^{45}$

\section{Pathogenesis and pathology}

The mechanisms underlying the pathogenesis of MERS-CoV remain to be defined because autopsies are generally not done either for religious and cultural reasons or to prevent environmental contamination with subsequent infection of health-care workers. Therefore, there are few data on the histopathological changes in patients with MERS-CoV infection, even in severe disease. ${ }^{46,47}$ The only two autopsies available show that viral infection was confined predominantly to the respiratory tract, although viral particles were detected in the kidney in one of the reports. ${ }^{47}$ Further, ex vivo human kidney cultures were shown to support productive MERS-CoV infection. ${ }^{48}$ However, it is not known whether infection of this organ contributes to worse outcomes compared with infections confined to the respiratory tract. Viral RNA, but not infectious MERS-CoV, was detected in the blood for at least 2 weeks after diagnosis. Whether this viral RNA represented an extrapulmonary infection is not clear, since MERS-CoV neutralising antibody was detected in the serum at the same time in some patients. ${ }^{49}$

Pathological changes in the lungs include evidence of focal haemorrhagic necrotising pneumonia with exudative diffuse alveolar damage, indistinguishable from findings detected in severe pneumonia caused by other viral agents.

Several experimentally infected animal models for MERS have been developed (appendix p 6)..$^{50,51}$ Methods for gene silencing and editing are being further developed, therefore it is likely that additional viral and host factors important in MERS-CoV pathogenesis will be identified.

Emirates, Seoul in South Korea and several cities in Saudi Arabia (appendix p 5). The 2013 outbreak in Al Hasa, Saudi Arabia, involved 23 people in three different hospitals and was linked to poor infection control practices, aerosol-generating procedures, continuous positive pressure ventilation, and cardiopulmonary resuscitation. ${ }^{42}$ In June, 2017, an outbreak of 34 MERS-CoV cases (including 17 in health-care workers) occurred in a hospital in Riyadh, Saudi Arabia, ${ }^{43}$ where the primary case was a 47-year-old man admitted for emergency intubation. Before a diagnosis of MERS, this individual had contact with 220 health-care workers, patients, and visitors. Another 2017 outbreak in Riyadh involved three hospitals, with 44 MERS cases in patients, health-care workers, and family members. The outbreak arose from three severely ill people who were diagnosed with MERS late in the disease course, and involved in a superspreading event. ${ }^{44}$ In 2015, South Korea had the largest MERS-CoV outbreak outside the Middle East with 186 cases reported, resulting from a single imported case from an individual who had returned from travelling in the Middle East. The outbreak included 185 secondary cases who acquired infection in

\section{Protective and deleterious immune responses}

MERS-CoV pathogenesis reflects a balance between coronavirus-induced protective and pathogenic host immune responses and direct cytotoxic effects of the virus. ${ }^{52}$ According to studies of patients infected with SARS-CoV and of mice and other animals infected experimentally with MERS-CoV, successful resolution of MERS and long-term protection from re-infection likely requires well coordinated innate and adaptive B-cell and T-cell responses. In patients with SARS, innate immune responses characterised by an extended period of cytokine secretion (eg, IFN $\alpha$ and IFN $\beta$ ) was correlated with delayed antibody responses and poor management outcomes; this prolonged innate response has not yet been shown in patients infected with MERS-CoV. ${ }^{53}$ MERS-CoV productively infects activated human $\mathrm{T}$ cells and induces delayed cytokine responses after infection of human myeloid cells in vitro, both of which could impair virus clearance and the development of an effective immune response. ${ }^{54-56}$ 
During the acute phase of MERS, robust virus-specific CD8 T-cell responses were detected in most patients with severe or moderate disease, with antibody and CD4 T-cell responses appearing later in the disease course. ${ }^{57} \mathrm{~T}$-cell and antibody responses were reliably detected $2-3$ weeks after diagnosis, although they were detected earlier in some patients. ${ }^{49,57}$ Studies of MERS survivors showed that MERS-CoV-specific antibody responses tended to be lower and transient in patients with mild or subclinical disease when compared with patients with severe disease, in whom MERS-CoV-specific antibody responses were detected for at least 2 years. ${ }^{57-60}$ In contrast, T-cell responses were detected in all MERS survivors for at least 2 years. ${ }^{59}$

The transitory nature of the antibody response in mild disease and greater stability of the T-cell response suggest that induction of both will be required for optimal longterm protection; the measurement of both will enhance the accuracy of prevalence studies.

\section{Clinical features \\ Incubation period}

The specific exposures that lead to sporadic MERS-CoV infections are unknown, therefore it is impossible to estimate the incubation period in primary cases. However, based on data from cases of human-to-human transmission, the incubation period is a median of 5-7 days, with a range of 2-14 days (median 5.2 days [95\% CI 1 -9-14-7]). ${ }^{2,10,21,61-63}$ Immunocompromised patients can present with longer incubation periods of up to 20 days. $^{64}$

\section{Presentation in adults}

The clinical presentation of patients infected with MERS-CoV ranges from asymptomatic or mild upper respiratory illness to rapidly progressive pneumonitis, respiratory failure, acute respiratory distress syndrome, septic shock, and multiorgan failure with fatal outcome (figure 5)..$^{2,1,11,61-70}$ It is not possible to distinguish patients with a legitimate asymptomatic MERS-CoV infection from those who develop mild disease because reports to WHO provide signs and symptoms information only at the time of reporting. Many individuals remain asymptomatic whereas some go on to develop mild disease, which is why WHO classifies these individuals as mild or asymptomatic. Asymptomatic-to-mild infection rates of $25-50 \%$ have been reported.

The signs and symptoms associated with MERS are non-specific, with or without multisystem involvement, and thus could be mistaken for other causes of respiratory tract or gastrointestinal illnesses., ${ }^{2,10,11,61-70}$ Therefore, the clinical diagnosis of MERS can be easily missed. Patients with MERS can typically present with fever, chills, rigors, headache, a non-productive cough, sore throat, arthralgia, and myalgia followed by dyspnoea. Other associated symptoms include coryza, nausea, vomiting, dizziness, sputum production, diarrhoea, and abdominal pain. Some patients with MERS can present
Panel 2: MERS prevention and interventions $s^{21,31,33,36,67}$

The pathogen: MERS-CoV

- Anti-viral therapeutics including host-directed therapies or immune-based therapies are in development.

Intermediate host reservoir: dromedary camels

- Vaccinating dromedary camels, the source for primary human infection, is a proposed approach to preventing human infection.

- A recombinant camelpox virus expressing the $S$ protein has been shown to induce neutralising antibodies in camels.

- As compared to older camels, juvenile camels have higher rates of viral shedding. Past infection is not protective.

Humans with contact with infected camels

- Basic hand hygiene practices.

- Gloves and face masks when handling infected camels and camel products.

- Pasteurising camel milk.

- Avoid ingesting raw camel meat, dairy products, or urine.

- Vaccine development for people with high camel exposure.

Human cases

- High clinical awareness of the possibility of MERS-CoV infection and making early diagnosis.

- Isolate suspected cases early and institute infection control measures.

- Face masks and hand hygiene measures for all HCW and family contacts.

- Occupationally exposed people have a higher risk of infection compared to the general public. Human surveillance is focused on diseased people, and those with subclinical or asymptomatic infection and could serve as a source of infection of a susceptible person with comorbidities.

\section{Nosocomial and community outbreaks}

- Nosocomial cases and outbreaks are diminishing due to institution of stringent infection control measures but still account for $35-50 \%$ of cases.

- More than 20 human vaccines have been developed and are being tested in animalssome are in human phase 1 or 2 trials.

MERS=Middle East respiratory syndrome. MERs-CoV=Middle East respiratory syndrome coronavirus.
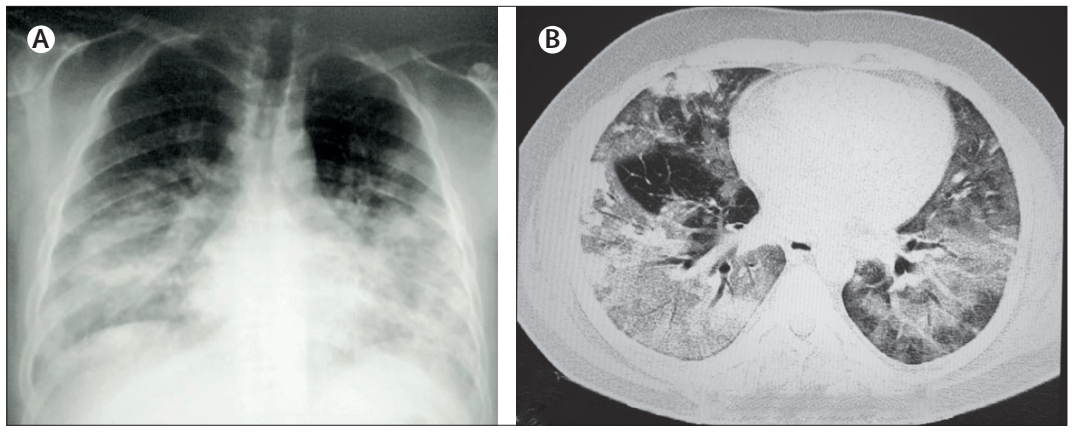

Figure 5: Chest imaging abnormalities in patients with Middle East respiratory syndrome (A) Chest $\mathrm{x}$-rays showing bilateral extensive diffuse and focal opacities. (B) Chest CT scan showing bilateral extensive ground-glass reticulonodular shadowing with bronchiolar wall thickening.

with atypical symptoms of mild respiratory illness without a fever and a gastrointestinal illness that precedes the development of pneumonia. ${ }^{64,67,68}$ Neuromuscular manifestations include hypersomnolence, weakness, and 
tingling in the extremities similar to Guillain-Barré syndrome or virus-related sensory neuropathy. ${ }^{68} \mathrm{Co}$ infection of MERS-CoV with other respiratory viruses (such as parainfluenza virus, rhinovirus, influenza A or B virus, respiratory syncytial virus, enteroviruses, and human metapneumovirus) and nosocomial bacterial infections has been reported in patients receiving intensive care. ${ }^{61,67}$

\section{Immunocompromised patients or those with comorbidities}

Immunocompromised patients or patients with chronic heart, liver, and kidney disease can present with atypical features, such as a longer incubation period, a longer period from initial PCR positivity to symptom onset, persistent prolonged viral shedding, and increased mortality. ${ }^{6470}$ MERS-CoV causes more severe disease in people older than 60 years, and those with chronic comorbid diseases such as renal disease, cancer, chronic lung disease, immunosuppression, and diabetes.

\section{Children, pregnant women, and returning travelers}

In children yonger than 5 years, MERS-CoV infection appears to be rare, and usually presents as mild disease with cough as the predominant clinical symptom. Acute and severe respiratory illness (ie, a fatal outcome after multiorgan failure) has been noted in only two of 38 reported paediatric cases and these were in boys aged 9 months and 2 years with comorbidities (infantile nephrotic syndrome and cystic fibrosis, respectively). ${ }^{7-74}$ Data on the prevalence of MERS-CoV in pregnant women are limited to case reports, and the clinical presentations and mortality rates are similar to nonpregnant women. ${ }^{75}$

MERS should be kept on the differential diagnosis list for ill travellers returning home from MERS-CoV endemic areas who present with acute febrile illness (temperature $\geq 38^{\circ} \mathrm{C}$ ), aches and pains, headache, cough, dyspnoea, diarrhoea, nausea, vomiting, unexplained leucopenia (white blood cell count $<3 \cdot 5 \times 110^{9} / \mathrm{L}$ ), and thrombocytopenia (platelets $<150 \times 10^{9} / \mathrm{L}$ ) - either with or without prominent respiratory symptoms. ${ }^{2,10,11,61-70}$ It is important that clinicians are alert to the possibility that patients could have MERS in all health-care settings where the virus is circulating so that an accurate diagnosis can be made and infection control measures implemented efficiently. ${ }^{76}$

\section{Clinical specimen types for diagnosis}

The type and quality of the clinical specimen are important in the laboratory diagnosis of MERS-CoV infection. Both upper respiratory tract specimens (oropharyngeal or nasopharyngeal swabs) and lower respiratory tract specimens (sputum, endotracheal aspirate or lavage) should be analysed whenever possible. ${ }^{\text {7-79 }}$ Patients with MERS might not shed the virus during the early stage of their illness; thus, initial negative results from upper respiratory samples do not rule out the possibility of MERS and patients should be retested using a lower respiratory tract sample. Several studies of MERS-CoV viral load measurements show that upper respiratory tract specimens have lower viral loads than lower respiratory specimens. ${ }^{11,1279,80}$ MERS-CoV RNA has been detected in blood, urine, and stool—but at much lower viral loads than in the respiratory tract. ${ }^{81,82}$

Clinical specimens must be collected by trained staff using appropriate personal protective equipmenteg, when taking nasopharyngeal and oropharyngeal specimens, Dacron or rayon swabs specifically designed for collecting specimens for virology must be used.7,78,83 These swab kits should contain virus transport medium. A single negative test result does not exclude the diagnosis and repeat sampling and testing is strongly recommended. ${ }^{83}$ A minimum of two samples, preferably from the lower respiratory tract, are needed to exclude MERS-CoV after initial assessment. To confirm clearance of the virus, respiratory samples should be collected sequentially (every 2 to 4 days) over ensuing days until there are two consecutive negative results at least $24 \mathrm{~h}$ apart in people who are clinically recovered.7

\section{Laboratory testing}

WHO guidelines for testing should be followed." MERS-CoV testing must be performed in appropriately equipped biosafety laboratories by staff trained in the relevant technical and safety procedures. National or WHO guidelines on the laboratory biosafety should be followed in all circumstances. ${ }^{83}$

Three real-time RT-PCR (rRT-PCR) assays for routine detection of MERS-CoV have been developed targeting upstream of the E protein gene (upE) and open reading frame (ORF) $1 \mathrm{~b}$ and ORF1a. The assay for the upE target is considered highly sensitive and is recommended for screening, with the ORF1a assay (ORF1a assay is considered more sensitive than ORF1b assay). ${ }^{\pi}$

An updated roadmap for MERS-CoV product development lists all available diagnostics and other diagnostics in the developmental phase. ${ }^{84}$ Several diagnostic tests are under development to accelerate turnaround times from sample analysis to result. ${ }^{85-87}$ A 2018 rapid and specific assay for the detection of MERS-CoV combines the reverse transcription loop-mediated isothermal amplification technique and a vertical flow visualisation strip (RT-LAMP-VF) to detect the nucleocapsid gene of MERS-CoV. ${ }^{86}$ The RT-LAMP-VF assay provides detection of MERS-CoV within $35 \mathrm{~min}$ and is easier to perform than the WHO-recommended rRT-PCR method. ${ }^{86}$

Several serological assays are available for detection of MERS-CoV: ELISA, recombinant spike immunofluorescent assay, and spike pseudoparticle neutralisation and microneutralisation assay. ${ }^{87-90} \mathrm{~A}$ case confirmed by serology requires evidence of seroconversion in two samples, ideally taken at least 14 days apart, by a screening (eg, ELISA, immunofluorescence assay) and a neutralisation assay. ${ }^{77,78}$ 


\section{Imaging}

A range of abnormal but non-specific chest $\mathrm{x}$-ray findings are seen in patients with MERS. ${ }^{11,92}$ These abnormalities include unilateral or bilateral bronchovascular shadowing, interstitial infiltrates, reticular opacities, reticulonodular shadowing, nodules, pleural effusions, and patchy to confluent consolidation (appendix pp 18-19). Lower lobes tend to be affected more than upper lobes early in the course of MERS and rapid opacification of lungs and progression to acute respiratory distress syndrome can occur.

High-resolution CT might show ground glass opacities (figure 5B) in early CT findings (with or without consolidation) followed by interlobular septal and intralobular interstitial thickening with peripheral and lower lobe involvement ${ }^{93,94}$ within the first week of MERS-CoV infection. During subsequent weeks, a so-called crazy-paving lung abnormality, cavitation, tree-in-bud pattern and centrilobular nodules, constrictive obliterative bronchiolitis, bronchiolitis obliterans, peribronchiolar air-trapping, thickened peripheral bronchioles, and organising pneumonia have been observed. ${ }^{95}$

\section{Treatment and management}

Currently, there are no specific anti-MERS-CoV therapies available for human use. The mainstay of clinical management of MERS cases is mostly symptom focused, providing supportive care ${ }^{10,61}$ with pain and fever management, treating concomitant or secondary bacterial infections, and supporting vital organ functions. Mild MERS cases can be managed at home. ${ }^{96}$ Predictive factors for development of pneumonia include older age (>56 years), high fever, thrombocytopenia, lymphopenia, C-reactive protein greater than or equal to $2 \mathrm{mg} / \mathrm{dL}$, and a high viral load in sputum (threshold cycle value of rRT-PCR <28 · 5). ${ }^{10,70}$ Respiratory failure and acute kidney injury (with haematuria and proteinuria) are common among patients admitted for hospital care because of the severity of their disease and who require mechanical ventilation, extracorporeal membrane oxygenation, and dialyses..$^{10,61,70}$

Several empirical treatments have been studied in severely ill patients. Therapies used for severely ill patients with MERS have included convalescent plasma, corticosteroids, antiviral agents (eg, interferons and ribavirin), and protease inhibitors, or combination of members from these groups. A systematic review of 30 publications on therapeutic agents used for MERS treatment in various outbreaks showed a complete absence of an accurate evidence base and emphasised the need for controlled trials. ${ }^{97}$

\section{Antiviral agents}

Several agents have shown inhibitory effects against MERS-CoV in cell cultures, including interferons, ribavirin, ciclosporin, and mycophenolic acid..$^{98-105}$ Empirical lopinavir-ritonavir, pegylated interferon alfa-2a, and ribavirin have been used for serious cases, but no efficacy data are yet available. There is an ongoing randomised clinical trial in progress in Saudi Arabia (the MIRACLE trial; NCT02845843) comparing lopinavir-ritonavir, recombinant interferon beta, and standard supportive care against placebo and standard supportive care in patients with laboratory-confirmed MERS requiring hospital admission. This recursive, multicentre, placebocontrolled, double-blind, randomised controlled trial is designed to include two components, each consisting of two stages. The first two-stage component is designed to adjust sample size and determine futility stopping, but not efficacy stopping $(n=34)$. The second two-stage component is designed to determine efficacy stopping and possibly readjustment of sample size.

\section{Convalescent plasma}

The use of plasma from patients with MERS who have made a full recovery (convalescent plasma) requires clinical trial evaluation. Preclinical animal data show that transfer of serum samples from MERS-CoVimmune camels to infected mice resulted in reduced weight loss and lung histopathology, ${ }^{106}$ thus suggesting therapeutic potential. In the 2015 Korean outbreak, three of 13 patients with MERS with respiratory failure were given four infusions of convalescent plasma. ${ }^{107}$ Two of three showed neutralising activity. Donor plasma with a plaque reduction neutralisation test (PRNT) titre of $1 / 80$ had a meaningful serological response after convalescent plasma infusion, while that with a PRNT titre of $1 / 40$ did not. The authors conclude that for effective convalescent plasma infusion in patients with MERS, donor plasma with a neutralisation activity of a PRNT titre greater than or equal to $1 / 80$ should be used.

\section{Antibiotic therapy}

Antibiotic therapy is commonly started empirically in seriously ill patients. A retrospective study of 136 patients with MERS found that macrolide therapy resulted in no reduction in mortality or faster MERS-CoV RNA clearance compared with those who were not treated with macrolides. ${ }^{108}$

\section{Intensive care management}

For serious cases, hospital inpatient care is required to reduce the risk of complications such as organ failure and secondary infections. Non-invasive ventilation is associated with a high failure rate $(92 \%)$ in patients with acute hypoxaemic respiratory failure due to MERS-CoV infection. ${ }^{109}$ Patients with severe symptoms might need to be managed in an intensive care unit, where lung-protective ventilatory strategies for acute respiratory distress syndrome, inotropic support, antimicrobial therapy for co-infections, and renal replacement therapy for acute renal failure can be provided. 
Panel 3: Potential therapies for the treatment of MERS coronavirus infection ${ }^{97-105,139-143}$

\section{Antibody-based interventions}

- Whole blood

- Convalescent plasma

- Intravenous immunoglobulin

- Polyclonal human immunoglobulin (SAB-301) from transgenic cows

- Equine antibody fragments

- Camel antibodies

- Monoclonal antibodies (eg, MERS-4, MERS-7)

- Human monoclonal antibodies to Sprotein

- Humanised anti-S monoclonals (eg, hMS-1, m336, 4C2)

Interferons

- Interferon alfa $(1 \mathrm{a}, 2 \mathrm{~b})$

- Interferon beta-1b

- Interferon gamma

Antivirals

- Ribavirin monotherapy (with or without interferon)

- HIV protease inhibitors (eg, lopinavir, nelfinavir)

- Cyclophilin inhibitors (eg, ciclosporin, alisporivir)

- Nucleoside viral RNA polymerase inhibitors (galidesivir, remdesivir, EIDD 2801 [prodrug of EIDD 1931]

\section{MERS-CoV 3 C-like protease inhibitors}

- Flavinoids (eg, herbacetin, isobavachalcone, quercetin 3- $\beta$-d-glucoside, helichrysetin)

Combination therapies

- Lopinavir-ritonavir and interferon beta $1 b$

- Cyclosporin plus interferon alpha

- Lopinavir-ritonavir

- Ribavirin and interferon alpha

Host-directed therapies (repurposed drugs)

- Chlorpromazine

- Mycophenolic acid (with or without interferon beta 1b)

- Nitazoxanide

- Sitagliptin

- Omacetaxine mepesuccinate

- Aciclovir

- Imatinib mesylate (tyrosine mesylate inhibitor)

- Neurotransmitter inhibitors (eg, clomipramine, astemizole)

- Neutriceuticals (eg, zinc)

Host-directed therapies (cellular therapy)

- Allogeneic mesenchymal stromal cells

Lectins

- Mannose binding lectin

Anti-coronavirus peptides

- Peptides derived from HR1, HR2, and RBD spike protein subunits

- Peptides inhibiting viral entry and replication

- Peptides derived from antimicrobial peptides

RNA interference molecules silencing key MERS-CoV genes

- miRNA molecules

- siRNA molecules

MERS=Middle East respiratory syndrome. MERS-CoV=Middle East respiratory syndrome coronavirus. $R B D=$ receptor-binding domain. $S=$ spike. RNA=ribonucleic acid. miRNA=micro RNA. siRNA=small interfering RNA.

\section{Systemic corticosteroids}

Studies show no benefit from the use of systemic corticosteroids. Systemic corticosteroids were shown to delay viral clearance in critically ill patients with MERS-CoV infection. ${ }^{100}$

\section{New treatments}

A range of potential treatments are under consideration, development, or evaluation (panel 3). A phase 1, first-inhuman, single site, randomised, double-blind, placebocontrolled study to evaluate the safety, tolerability, pharmacokinetics, and immunogenicity of single ascending doses of a co-administered monoclonal antibodies REGN3048 and REGN3051 administered intravenously in healthy adult volunteers (NCT03301090) is ongoing and study duration will be approximately 16 months. Another study is comparing patients who received extracorporeal membrane oxygenation (ECMO) support with those who did not receive ECMO support (NCT02627378). Several monoclonal and polyclonal neutralising antibody products, including novel chimeric camel or human heavychain antibodies, are protective in animal models, ${ }^{110-112}$ and their potential use for pre-exposure or post-exposure prophylaxis in outbreak management requires evaluations in controlled trials.

\section{Mental health support}

In a mental health study, $7 \cdot 6 \%$ of 1656 patients who were quarantined showed symptoms of anxiety, and $6.4 \%$ reported feelings of anger during the 2 weeks of quarantine. ${ }^{113}$ Mental health support, accurate information, and appropriate supplies, including food, clothes, and accommodation, should be provided to people who feel isolated.

\section{Management outcomes and mortality rates}

Several studies have reported disease severity and mortality risk factor data from patients in the Middle East and South Korea. ${ }^{11,12,21,114-117}$ Ahmed and colleagues collected the daily information on MERS-CoV cases posted online by the Saudi Arabian Ministry of Health between Dec 2, 2014, and Nov 12, 2016, and reviewed 660 laboratory-confirmed cases of MERS. ${ }^{114}$ They showed mortality at day $3(13 \cdot 8 \%)$, day $30(28 \cdot 3 \%)$, and overall $(29 \cdot 8 \%)$. Patients older than 60 years were more likely to die $(45 \cdot 2 \%$ mortality) from their infections than were younger patients $(20 \%)$.

Several factors are associated with severe disease and high mortality rates in patients with MERS. These factors include male sex, comorbid pre-existing illnesses (such as obesity, diabetes mellitus, cancer, chronic heart, lung, and kidney disease, and immunocompromised states), low serum albumin, thrombocytopenia, lymphopenia, concomitant infections, and positive plasma MERS-CoV RNA. DPP4 receptors are upregulated in the lungs of smokers and patients with chronic obstructive pulmonary disease, which might explain why patients with comorbid 
Panel 4: Priorities for MERS research, surveillance, management, and control

\section{Establishing a One Health global consortium:}

- Creation of a One Health multidisciplinary consortia in Middle Eastern and African countries to tackle zoonotic spread of MERS-CoV between animals, humans, and the environment and to monitor, respond to, and prevent major outbreaks

- Establishing effective One Health research and surveillance collaborations between a range of expertise including public health officers, physicians, veterinarians, animal husbandry specialists, agriculturalists, ecologists, phylogeneticists, trialists, and basic scientists

Priority studies in dromedary camels:

- Natural history studies that evaluate evidence of re-infection

- Value chain and production system analyses

- Improving surveillance to evaluate any seasonal or temporal variation in viral shedding

- Identifying important points for interventions and interruption of within-species and zoonotic transmission

- Accelerating the development of camel vaccine candidates

Priority studies at the animal-human-environmental interface:

- Real-time mapping of virus circulation and geographical range of MERS-CoV infection in humans and dromedary camels

- Development of new accurate and accessible point-of-care diagnostic tests for outbreak containment, case management, and surveillance

- Evaluating geographical extent of spillover from animals to humans in Africa, the Middle East, and south Asia

- Animal and human serological, virological, and genomic studies in specific locations to evaluate risk factors for human infection and exact routes of zoonotic transmission, including food and oral routes

- Social science and anthropological studies to describe and quantify exposures to dromedary camels and identify opportunities for risk-mitigating interventions
Priority studies in human populations:

- Accelerating research and development, implementation, and evaluation of medical countermeasures to reduce morbidity and mortality associated with MERS (especially in high risk comorbid populations)

- Identifying optimal interventions for reducing infection among health-care workers in hospital settings

- Determining the role of asymptomatic cases in transmission of infections in humans and whether any specific behaviours can result in human infection from non-human sources

- Targeted epidemiological studies in clinical settings to better understand immune response and duration of infectiousness and address the long-term medical and psychological complications in MERS survivors

- Integrating testing for MERS-CoV into existing respiratory disease surveillance systems to identify extent and spectrum of mild infection in the community

Priority studies for vaccines, therapeutics, and rapid diagnostics:

- Accelerating the development of human MERS-CoV vaccine candidates

- Accelerating development of MERS-CoV therapeutic pipeline and host-directed therapies

- Development of new accurate and accessible diagnostic tests for outbreak containment, case management, and surveillance

- Increased donor investment into research and development for: novel point-of-care testing options, syndromic panels for differential diagnosis, a greater understanding of viral and antibody kinetics, improved access to clinical specimens, and establishment of international reference standards

Adapted from the FAO-OIE-WHO MERS Technical Working Group's report on MERS (2018). MERS=Middle East respiratory syndrome. ${ }^{31}$ MERS-CoV=Middle East respiratory syndrome coronavirus. lung diseases are prone to severe illness. ${ }^{118}$ In the 2015 Korean outbreak, the case-fatality rate was $20 \cdot 4 \%$ (39 of 186 patients died), the in-hospital mortality was 19.4\% (36 of 186 patients), 7-day mortality (from symptom onset) was $3 \cdot 8 \%$ (seven of 186 ), and 28 -day mortality was $17.7 \%$ (33 of 186). ${ }^{11,12}$ Host factors associated with mortality in this outbreak were older age ( $>60$ years), smoking history, pre-existing pneumonia, abnormal renal function, and comorbidity. Low albumin, altered mentality, and high pneumonia severity index score at admission were risk factors for mortality.

\section{Prognosis and long term follow-up of MERS survivors}

In a study of long-term effects after recovery from MERS, ${ }^{119}$ patients with severe illness who were admitted to intensive care reported higher limitations in some measure of their quality of life than patients with less severe illness who were managed in medical wards. The long-term consequences of MERS illness on survivors appear to be similar to those caused by other viral causes of severe acute respiratory infections such as influenza, parainfluenza, and metapneumovirus. ${ }^{120}$ Follow-up imaging studies of patients who recover from MERS indicate that lung fibrosis might develop in a substantial number of patients. ${ }^{95}$

\section{Prevention}

The prevention of transmission of MERS-CoV in the community and in health-care settings is crucial to preventing outbreaks and further spread. Several substantive reviews and WHO guidelines are available on the subject. ${ }^{21,61,76,96}$ 
It is important to maintain good personal and environmental hygiene, and to implement stringent contact and droplet precautions among health-care workers. To prevent community transmission, contact tracing, quarantine or isolation of close contacts, and public education are important measures. ${ }^{20,60}$

In hospitals, early case detection followed by isolation is essential, ideally in negative pressure isolation rooms. The main infection prevention and control measures for managing patients with MERS are well documented from the SARS epidemic and from experiences from managing MERS outbreaks (appendix pp 7-8).

\section{Advances in vaccine development}

Advances in technology, vaccine platforms, clinical trial designs, and bioinformatics are supporting MERS-CoV vaccine development (appendix pp 8-9). WHO target product profiles for MERS-CoV vaccines calls for the development of three types of MERS vaccines: a human vaccine for long-term protection of people at high exposure risk, such as health-care workers and those working with potentially infected camels; a human vaccine for reactive use in outbreak settings; and a dromedary camel vaccine to prevent zoonotic transmission. ${ }^{121}$ Multiple types of vaccine candidates are in development including inactivated whole virus, live attenuated virus, viral vectored vaccines, subunit vaccines, and DNA vaccines. ${ }^{121,122}$ Most vaccines use the $S$ protein or the domain of the $S$ protein required for binding to host DPP4 as an immunogen, since neutralising antibodies are mostly directed to the receptor binding domain.

\section{Priorities for MERS research, surveillance, management, and control}

WHO, Food and Agriculture Organization of the UN, and World Organization for Animal Health, in consultation with global MERS community, identified knowledge gaps and priorities for MERS research, surveillance, management, and control (panel 4). ${ }^{33}$

Several recent publications have highlighted the importance of a one-human-environmental-animal-health (One Health) approach to tackle and control the spread of MERS-CoV (appendix p 9). ${ }^{31,121-126}$

\section{Conclusion}

MERS-CoV is a pathogen with epidemic potential that continues to cause sporadic human disease and remains on the WHO Blueprint 2020 priority list. ${ }^{4}$ Given that MERS-CoV appears to be highly endemic among dromedary camels from geographically widespread areas of the Middle East and Africa, zoonotic transmission with consequent risk of human epidemics will most likely continue for years to come. ${ }^{8,9}$ MERS-CoV endemic and at-risk countries must invest more in surveillance, in public health research, and in medical interventionsincluding human and camel vaccine development. The continued risk of human MERS-CoV outbreaks 7 years after its first discovery, effective human and camel MERS-CoV vaccines appear to be the ideal way to prevent continuing spread of MERS-CoV in dromedary camels in the Middle East and in humans at high risk of acquiring community and nosocomial MERS-CoV infection.

\section{Contributors}

This paper was conceptualised by ZAM and AZ. All authors contributed equally to the literature search, writing, and reviewing of the manuscript.

\section{Declaration of interests}

We declare no competing interests.

\section{Acknowledgments}

AZ acknowledges support from the PANDORA-ID-NET (grant RIA2016E-1609) funded by the European and Developing Countries Clinical Trials Partnership (EDCTP2) under Horizon 2020, the EU's Framework Programme for Research and Innovation. AZ is the recipient of a UK National Institutes of Health Research senior investigator award. SP is supported by grants from the US National Institutes of Health (PO1 AI060699 RO1 AI129269). We thank Samantha Mackin (University of Iowa) for creating figure 1 on the basis of a template provided by Benjamin W Neuman (Texas A\&M-Texarkana) and Michael J Buchmeier (University of California, Irvine)

Editorial note: the Lancet Group takes a neutral position with respect to territorial claims in published maps and institutional affiliations.

\section{References}

1 WHO. SARS (severe acute respiratory syndrome). https://www. who.int/ith/diseases/sars/en/ (accessed Feb 12, 2020).

2 WHO. Middle East respiratory syndrome coronavirus (MERS-CoV). https://www.who.int/emergencies/mers-cov/en/ (accessed Feb 12, 2020).

3 WHO. Coronavirus disease (COVID-19) outbreak. https://www. who.int/emergencies/diseases/novel-coronavirus-2019 (accessed Feb 23, 2020).

4 WHO. A research and development blueprint for action to prevent epidemics. https://www.who.int/blueprint/en/ (accessed Feb 15, 2020).

5 Peiris JS, Yuen KY, Osterhaus AD, Stöhr K. The severe acute respiratory syndrome. N Engl J Med 2003; 349: 2431-41.

6 Zaki AM, van Boheemen S, Bestebroer TM, Osterhaus AD Fouchier RA. Isolation of a novel coronavirus from a man with pneumonia in Saudi Arabia. N Engl J Med 2012; 367: 1814-20.

7 Hijawi B, Abdallat M, Sayaydeh A, et al. Novel coronavirus infections in Jordan, April 2012: epidemiological findings from a retrospective investigation. East Mediterr Health J 2013; 19: $\mathrm{S} 12-8$

8 Drosten C, Kellam P, Memish ZA. Evidence for camel-to-human transmission of MERS coronavirus. N Engl J Med 2014; 371: 1359-60.

9 El-Kafrawy SA, Corman VM, Tolah AM, et al. Enzootic patterns of Middle East respiratory syndrome coronavirus in imported African and local Arabian dromedary camels: a prospective genomic study. Lancet Planet Health 2019; 3: e521-28.

10 Zumla A, Hui DS, Perlman S. Middle East respiratory syndrome. Lancet 2015; 386: 995-1007.

11 Kim KH, Tandi TE, Choi JW, Moon JM, Kim MS. Middle East respiratory syndrome coronavirus (MERS-CoV) outbreak in South Korea, 2015: epidemiology, characteristics and public health implications. J Hosp Infect 2017; 95: 207-13.

12 Oh MD, Park WB, Park SW, et al. Middle East respiratory syndrome: what we learned from the 2015 outbreak in the Republic of Korea. Korean J Intern Med 2018; 33: 233-46.

13 Zhu N, Zhang D, Wang W et al. A novel coronavirus from patients with pneumonia in China, 2019. N Engl J Med 2020; published online January 24. DOI:10.1056/NEJMoa2001017.

14 Masters PS, Perlman S. Coronaviridae. In: Knipe DM, Howley PM, eds. Fields virology. Philadelphia, PA: Lippincott Williams \& Wilkins, 2013: 825-58.

15 Raj VS, Mou H, Smits SL, et al. Dipeptidyl peptidase 4 is a functional receptor for the emerging human coronavirus-EMC. Nature 2013; 495: 251-54. 
16 Walls AC, Tortorici MA, Bosch BJ, et al. Cryo-electron microscopy structure of a coronavirus spike glycoprotein trimer. Nature 2016; 531: 114-17.

17 Yuan Y, Cao D, Zhang Y, et al. Cryo-em structures of MERS-CoV and SARS-CoV spike glycoproteins reveal the dynamic receptor binding domains. Nat Commun 2017; 8: 15092.

18 Fehr AR, Perlman S. Coronaviruses: an overview of their replication and pathogenesis. Methods Mol Biol 2015; 1282: 1-23.

19 WHO. Middle East respiratory syndrome coronavirus: case definition for reporting to WHO. https://www.who.int/csr/disease/ coronavirus_infections/case_definition/en/ (accessed Aug 30, 2017).

20 Conzade R, Grant R, Malik MR, et al. Reported direct and indirect contact with dromedary camels among laboratory-confirmed MERS-CoV cases. Viruses 2018; 10: 425.

21 Hui DS, Azhar EI, Kim YJ, Memish ZA, Oh MD, Zumla A. Middle East respiratory syndrome coronavirus: risk factors and determinants of primary, household, and nosocomial transmission. Lancet Infect Dis 2018; 18: e217-27.

22 Kandeil A, Gomaa M, Nageh A, et al. Middle East respiratory syndrome coronavirus (MERS-CoV) in dromedary camels in Africa and Middle East. Viruses 2019; 11: 717.

23 Reusken CB, Ababneh M, Raj VS, et al. Middle East respiratory syndrome coronavirus (MERS-CoV) serology in major livestock species in an affected region in Jordan, June to September 2013. Euro Surveill 2013; 18: 20662.

24 Azhar EI, El-Kafrawy SA, Farraj SA, et al. Evidence for camel-tohuman transmission of MERS coronavirus. N Engl J Med 2014; 370: 2499-505.

25 Haagmans BL, Al Dhahiry SH, Reusken CB, et al. Middle East respiratory syndrome coronavirus in dromedary camels: an outbreak investigation. Lancet Infect Dis 2014; 14: 140-45.

26 Paden CR, Yusof M, Al Hammadi ZM, et al. Zoonotic origin and transmission of Middle East respiratory syndrome coronavirus in the UAE. Zoonoses Public Health 2018; 65: 322-33.

27 Adney DR, van Doremalen N, Brown VR, et al. Replication and shedding of MERS-CoV in upper respiratory tract of inoculated dromedary camels. Emerg Infect Dis 2014; 20: 1999-2005.

28 Khalafalla AI, Lu X, Al-Mubarak AI, Dalab AH, Al-Busadah KA, Erdman DD. MERS-CoV in upper respiratory tract and lungs of dromedary camels, Saudi Arabia, 2013-2014. Emerg Infect Dis 2015; 21: $1153-58$.

29 Sikkema RS, Farag E, Islam M, et al. Global status of Middle East respiratory syndrome coronavirus in dromedary camels: a systematic review. Epidemiol Infect 2019; 147: e84.

30 Sabir JS, Lam TT, Ahmed MM, et al. Co-circulation of three camel coronavirus species and recombination of MERS-CoVs in Saudi Arabia. Science 2016; 351: 81-84.

31 FAO-OIE-WHO MERS Technical Working Group. MERS: progress on the global response, remaining challenges and the way forward. Antiviral Res 2018; 159: 35-44.

32 Kim JI, Park S, Bae JY, Park MS. Evolutionary relationship analysis of Middle East respiratory syndrome coronavirus $4 \mathrm{a}$ and $4 \mathrm{~b}$ protein coding sequences. J Vet Sci 2019; 20: e1.

33 Elkholy AA, Grant R, Assiri A, Elhakim M, Malik MR, Van Kerkhove MD. MERS-CoV infection among healthcare workers and risk factors for death: retrospective analysis of all laboratoryconfirmed cases reported to WHO from 2012 to 2 June 2018. J Infect Public Health 2019; published online May 2. DOI:10.1016/j.jiph.2019.04.011.

34 Al Hammadi ZM, Chu DK, Eltahir YM, et al. Asymptomatic MERS-CoV infection in humans possibly linked to infected dromedaries imported from Oman to United Arab Emirates, May 2015. Emerg Infect Dis 2015; 21: 2197-200.

35 Alraddadi BM, Al-Salmi HS, Jacobs-Slifka K, et al. Risk factors for Middle East respiratory syndrome coronavirus infection among healthcare personnel. Emerg Infect Dis 2016; 22: 1915-20.

36 Farag EA, Reusken CB, Haagmans BL, et al. High proportion of MERS-CoV shedding dromedaries at slaughterhouse with a potential epidemiological link to human cases, Qatar 2014. Infect Ecol Epidemiol 2015; 5: 28305.

37 Kasem S, Qasim I, Al-Hufofi A, et al. Cross-sectional study of MERS-CoV-specific RNA and antibodies in animals that have had contact with MERS patients in Saudi Arabia. J Infect Public Health 2018; 11: 331-38.
38 Muhairi SA, Hosani FA, Eltahir YM, et al. Epidemiological investigation of Middle East respiratory syndrome coronavirus in dromedary camel farms linked with human infection in Abu Dhabi Emirate, United Arab Emirates. Virus Genes 2016; 52: 848-54.

39 Zhou J, Li C, Zhao G, et al. Human intestinal tract serves as an alternative infection route for Middle East respiratory syndrome coronavirus. Sci Adv 2017; 3: eaao4966.

40 Bernard-Stoecklin S, Nikolay B, Assiri A, et al. Comparative analysis of eleven healthcare-associated outbreaks of Middle East respiratory syndrome coronavirus (MERS-CoV) from 2015 to 2017. Sci Rep 2019; 9: 7385.

41 Choi S, Jung E, Choi BY, Hur YJ, Ki M. High reproduction number of Middle East respiratory syndrome coronavirus in nosocomial outbreaks: mathematical modelling in Saudi Arabia and South Korea. J Hosp Infect 2018; 99: 162-68.

42 Assiri A, McGeer A, Perl TM, et al. Hospital outbreak of Middle East respiratory syndrome coronavirus. N Engl J Med 2013; 369: 407-16.

43 Alanazi KH, Killerby ME, Biggs HM, et al. Scope and extent of healthcare-associated Middle East respiratory syndrome coronavirus transmission during two contemporaneous outbreaks in Riyadh, Saudi Arabia, 2017. Infect Control Hosp Epidemiol 2019; 40: 79-88.

44 Amer H, Alqahtani AS, Alzoman H, Aljerian N, Memish ZA. Unusual presentation of Middle East respiratory syndrome coronavirus leading to a large outbreak in Riyadh during 2017. Am J Infect Control 2018; 46: 1022-25.

45 Kang CK, Song KH, Choe PG, et al. Clinical and epidemiologic characteristics of spreaders of Middle East respiratory syndrome coronavirus during the 2015 outbreak in Korea. J Korean Med Sci 2017; 32: 744-49.

46 Alsaad KO, Hajeer AH, Al Balwi M, et al. Histopathology of Middle East respiratory syndrome coronovirus (MERS-CoV) infection-clinicopathological and ultrastructural study. Histopathology 2018; 72: 516-24.

47 Ng DL, Al Hosani F, Keating MK, et al. Clinicopathologic, immunohistochemical, and ultrastructural findings of a fatal case of Middle East respiratory syndrome coronavirus infection in the United Arab Emirates, April 2014. Am J Pathol 2016; 186: 652-58.

48 Yeung ML, Yao Y, Jia L, et al. MERS coronavirus induces apoptosis in kidney and lung by upregulating Smad7 and FGF2. Nat Microbiol 2016; 1: 16004

49 Corman VM, Albarrak AM, Omrani AS, et al. Viral shedding and antibody response in 37 patients with Middle East respiratory syndrome coronavirus infection. Clin Infect Dis 2016; 62: 477-83.

50 Widagdo W, Sooksawasdi Na Ayudhya S, Hundie GB, et al. Host determinants of MERS-CoV transmission and pathogenesis. Viruses 2019; 11: E280.

51 Leist SR, Cockrell AS. Genetically engineering a susceptible mouse model for MERS-CoV-induced acute respiratory distress syndrome. Methods Mol Biol 2020; 2099: 137-59.

52 Channappanavar R, Perlman S. Pathogenic human coronavirus infections: causes and consequences of cytokine storm and immunopathology. Semin Immunopathol 2017; 39: 529-39.

53 Cameron MJ, Ran L, Xu L, et al. Interferon-mediated immunopathological events are associated with atypical innate and adaptive immune responses in patients with severe acute respiratory syndrome. J Virol 2007; 81: 8692-706.

54 Chu H, Zhou J, Wong BH, et al. Productive replication of Middle East respiratory syndrome coronavirus in monocyte-derived dendritic cells modulates innate immune response. Virology 2014; 454-455: 197-205.

55 Lau SK, Lau CC, Chan KH, et al. Delayed induction of proinflammatory cytokines and suppression of innate antiviral response by the novel Middle East respiratory syndrome coronavirus: implications for pathogenesis and treatment. J Gen Virol 2013; 94: 2679-90.

56 Zhou J, Chu H, Li C, et al. Active replication of Middle East respiratory syndrome coronavirus and aberrant induction of inflammatory cytokines and chemokines in human macrophages: implications for pathogenesis. J Infect Dis 2014; 209: 1331-42.

57 Shin HS, Kim Y, Kim G, et al. Immune responses to Middle East respiratory syndrome coronavirus during the acute and convalescent phases of human infection. Clin Infect Dis 2019; 68: 984-92. 
58 Drosten C, Meyer B, Müller MA, et al. Transmission of MERS-coronavirus in household contacts. N Engl J Med 2014; 371: 828-35.

59 Zhao J, Alshukairi AN, Baharoon SA, et al. Recovery from the Middle East respiratory syndrome is associated with antibody and T-cell responses. Sci Immunol 2017; 2: eaan5393.

60 Alshukairi AN, Khalid I, Ahmed WA, et al. Antibody response and disease severity in healthcare worker MERS survivors. Emerg Infect Dis 2016; 22: 1113-15.

61 Arabi YM, Balkhy HH, Hayden FG, et al. Middle East respiratory syndrome. N Engl J Med 2017; 376: 584-94.

62 Cauchemez S, Fraser C, Van Kerkhove MD, et al. Middle East respiratory syndrome coronavirus: quantification of the extent of the epidemic, surveillance biases, and transmissibility. Lancet Infect Dis 2014; 14: 50-56.

63 Breban R, Riou J, Fontanet A. Interhuman transmissibility of Middle East respiratory syndrome coronavirus: estimation of pandemic risk. Lancet 2013; 382: 694-99.

64 Kim SH, Ko JH, Park GE, et al. Atypical presentations of MERS-CoV infection in immunocompromised hosts. J Infect Chemother 2017; 23: 769-73.

65 Drosten C, Seilmaier M, Corman VM, et al. Clinical features and virological analysis of a case of Middle East respiratory syndrome coronavirus infection. Lancet Infect Dis 2013 13: 745-51.

66 Grant R, Malik MR, Elkholy A, Van Kerkhove MD. A review of asymptomatic and sub-clinical Middle East respiratory syndrome coronavirus infections. Epidemiol Rev 2019; published online Nov 29. DOI:10.1093/epirev/mxz009.

67 WHO MERS-CoV Research Group. State of knowledge and data gaps of Middle East respiratory syndrome coronavirus (MERS-CoV) in humans. PLoS Curr 2013; 5.

68 Kim JE, Heo JH, Kim HO, et al. Neurological complications during treatment of Middle East respiratory syndrome. J Clin Neurol 2017; 13: 227-33.

69 Alfaraj SH, Al-Tawfiq JA, Altuwaijri TA, Alanazi M, Alzahrani N, Memish ZA. Middle east respiratory syndrome coronavirus transmission among health care workers: implication for infection control. Am J Infect Control 2018; 46: 165-68

70 Hui DS, Memish ZA, Zumla A. Severe acute respiratory syndrome vs the Middle East respiratory syndrome. Curr Opin Pulm Med 2014 20: 233-41.

71 Al-Tawfiq JA, Kattan RF, Memish ZA. Middle East respiratory syndrome coronavirus disease is rare in children: an update from Saudi Arabia. World J Clin Pediatr 2016; 5: 391-96.

72 Alfaraj SH, Al-Tawfiq JA, Altuwaijri TA, Memish ZA. Middle East respiratory syndrome coronavirus in pediatrics: a report of seven cases from Saudi Arabia. Front Med 2019; 13: 126-30.

73 Memish ZA, Al-Tawfiq JA, Assiri A, et al. Middle East respiratory syndrome coronavirus disease in children. Pediatr Infect Dis J 2014; 33: 904-06.

74 Mobaraki K, Ahmadzadeh J. Current epidemiological status of Middle East respiratory syndrome coronavirus in the world from 1.1.2017 to 17.1.2018: a cross-sectional study. BMC Infect Dis 2019; 19: 351.

75 Alfaraj SH, Al-Tawfiq JA, Memish ZA. Middle East respiratory syndrome coronavirus (MERS-CoV) infection during pregnancy: report of two cases \& review of the literature. J Microbiol Immunol Infect 2019; 52: 501-03.

76 WHO. Infection prevention and control during health care for probable or confirmed cases of Middle East respiratory syndrome coronavirus (MERS-CoV) infection. 2015. https://www.who.int/csr/ disease/coronavirus_infections/ipc-mers-cov/en/ (accessed Sept 26, 2019)

77 WHO. Laboratory testing for middle east respiratory syndrome coronavirus. 2018. https://apps.who.int/iris/bitstream/ handle/10665/259952/WHO-MERS-LAB-15.1-Rev1-2018-eng. pdf? sequence $=1$ (accessed Oct 3, 2019).

78 CDC. CDC laboratory testing for Middle East respiratory syndrome coronavirus (MERS-CoV). https://www.cdc.gov/coronavirus/mers/ lab/lab-testing.html (accessed Feb 21, 2020).

79 Memish ZA, Al-Tawfiq JA, Makhdoom HQ, et al. Respiratory tract samples, viral load, and genome fraction yield in patients with Middle East respiratory syndrome. J Infect Dis 2014; 210: 1590-94.
80 Oh MD, Park WB, Choe PG, et al. Viral load kinetics of MERS coronavirus infection. N Engl J Med 2016; 375: 1303-05.

81 Bermingham A, Chand MA, Brown CS, et al. Severe respiratory illness caused by a novel coronavirus, in a patient transferred to the United Kingdom from the Middle East, September 2012. Euro Surveill 2012; 17: 20290.

82 Alfaraj SH, Al-Tawfiq JA, Memish ZA. Middle east respiratory syndrome coronavirus intermittent positive cases: implications for infection control. Am J Infect Control 2019; 47: 290-93.

83 WHO. Laboratory biorisk management for laboratories handling human specimens suspected of confirmed to contain novel coronavirus: interim recommendations 2013. https://www.who.int/ csr/disease/coronavirus_infections/Biosafety_

InterimRecommendations_NovelCoronavirus_19Feb13.pdf?ua=1 (accessed Oct 3, 2019).

84 Kelly-Cirino C, Mazzola LT, Chua A, Oxenford CJ, Van Kerkhove MD. An updated roadmap for MERS-CoV research and product development: focus on diagnostics. BMJ Glob Health 2019; 4: e001105

85 Frans G, Beuselinck K, Peeters B, et al. Migrating a lab-developed MERS-CoV real-time PCR to 3 "sample to result" systems: experiences on optimization and validation. Diagn Microbiol Infect Dis 2019; 94: 349-54

86 Huang $\mathrm{P}$, Wang $\mathrm{H}$, Cao Z, et al. A rapid and specific assay for the detection of MERS-CoV. Front Microbiol 2018; 9: 1101.

87 Hashem AM, Al-Amri SS, Al-Subhi TL, et al. Development and validation of different indirect ELISAS for MERS-CoV serological testing. J Immunol Methods 2019; 466: 41-46.

88 Park SW, Perera RA, Choe PG, et al. Comparison of serological assays in human Middle East respiratory syndrome (MERS)coronavirus infection. Euro Surveill 2015; 20: 1-5.

89 Perera RA, Wang P, Gomaa MR, et al. Seroepidemiology for MERS coronavirus using microneutralisation and pseudoparticle virus neutralisation assays reveal a high prevalence of antibody in Dromedary camels in Egypt, June 2013. Euro Surveill 2013; 18: 20574.

90 Okba NMA, Raj VS, Widjaja I, et al. Sensitive and specific detection of low-level antibody responses in mild Middle East respiratory syndrome coronavirus infections. Emerg Infect Dis 2019; 25: 1868-77.

91 Das KM, Lee EY, Al Jawder SE, et al. Acute Middle East respiratory syndrome coronavirus: temporal lung changes observed on the chest radiographs of 55 patients. AJR Am J Roentgenol 2015; 205: W267-74.

92 Das KM, Lee EY, Langer RD, Larsson SG. Middle East respiratory syndrome coronavirus: what does a radiologist need to know? AJR Am J Roentgenol 2016; 206: 1193-201.

93 Ajlan AM, Ahyad RA, Jamjoom LG, Alharthy A, Madani TA. Middle East respiratory syndrome coronavirus (MERS-CoV) infection: chest CT findings. AJR Am J Roentgenol 2014; 203: 782-87.

94 Das KM, Lee EY, Enani MA, et al. CT correlation with outcomes in 15 patients with acute Middle East respiratory syndrome coronavirus. AJR Am J Roentgenol 2015; 204: 736-42.

95 Das KM, Lee EY, Singh R, et al. Follow-up chest radiographic findings in patients with MERS-CoV after recovery. Indian J Radiol Imaging 2017; 27: 342-49.

96 WHO. Home care for patients with Middle East respiratory syndrome coronavirus (MERS-CoV) infection presenting with mild symptoms and management of contacts interim guidance, June 2018 https://apps.who.int/iris/bitstream/handle/10665/272948/WHOMERS-IPC-18.1-eng.pdf?ua=1 (accessed Feb 24, 2020).

97 Momattin H, Al-Ali AY, Al-Tawfiq JA. A systematic review of therapeutic agents for the treatment of the Middle East respiratory syndrome coronavirus (MERS-CoV). Travel Med Infect Dis 2019; 30: 9-18.

98 Arabi Y, Balkhy H, Hajeer AH, et al. Feasibility, safety, clinical, and laboratory effects of convalescent plasma therapy for patients with Middle East respiratory syndrome coronavirus infection: a study protocol. Springerplus 2015; 4: 709.

99 Arabi YM, Alothman A, Balkhy HH, et al. Treatment of Middle East respiratory syndrome with a combination of lopinavir-ritonavir and interferon-beta1b (MIRACLE trial): study protocol for a randomized controlled trial. Trials 2018; 19: 81

100 Arabi YM, Mandourah Y, Al-Hameed F, et al. Corticosteroid therapy for critically ill patients with Middle East respiratory syndrome. Am J Respir Crit Care Med 2018; 197: 757-67. 
101 Behzadi MA, Leyva-Grado VH. Overview of current therapeutics and novel candidates against influenza, respiratory syncytial virus, and Middle East respiratory syndrome coronavirus infections. Front Microbiol 2019; 10: 1327.

102 Beigel JH, Nam HH, Adams PL, et al. Advances in respiratory virus therapeutics-a meeting report from the 6th ISIRV antiviral group conference. Antiviral Res 2019; 167: 45-67.

103 Rabaan AA, Alahmed SH, Bazzi AM, Alhani HM. A review of candidate therapies for Middle East respiratory syndrome from a molecular perspective. J Med Microbiol 2017; 66: 1261-74.

104 Zhou Y, Yang Y, Huang J, Jiang S, Du L. Advances in MERS-CoV vaccines and therapeutics based on the receptor-binding domain. Viruses 2019; 11: 60 .

105 Zumla A, Chan JF, Azhar EI, Hui DS, Yuen KY. Coronavirusesdrug discovery and therapeutic options. Nat Rev Drug Discov 2016 15: $327-47$.

106 Zhao J, Perera RA, Kayali G, Meyerholz D, Perlman S, Peiris M. Passive immunotherapy with dromedary immune serum in an experimental animal model for Middle East respiratory syndrome coronavirus infection. J Virol 2015; 89: 6117-20.

107 Ko JH, Seok H, Cho SY, et al. Challenges of convalescent plasma infusion therapy in Middle East respiratory coronavirus infection: a single centre experience. Antivir Ther 2018; 23: 617-22.

108 Arabi YM, Deeb AM, Al-Hameed F, et al. Macrolides in critically ill patients with Middle East respiratory syndrome. Int $J$ Infect Dis 2019; 81: 184-90.

109 Alraddadi BM, Qushmaq I, Al-Hameed FM, et al. Noninvasive ventilation in critically ill patients with the Middle East respiratory syndrome. Influenza Other Respir Viruses 2019; 13: 382-90.

110 Stalin Raj V, Okba NMA, Gutierrez-Alvarez J, et al. Chimeric camel/ human heavy-chain antibodies protect against MERS-CoV infection. Sci Adv 2018; 4: eaas9667.

111 Wang L, Shi W, Chappell JD, et al. Importance of neutralizing monoclonal antibodies targeting multiple antigenic sites on the Middle East respiratory syndrome coronavirus spike glycoprotein to avoid neutralization escape. J Virol 2018; 92: e02002-17.

112 Widjaja I, Wang C, van Haperen R, et al. Towards a solution to MERS: protective human monoclonal antibodies targeting different domains and functions of the MERS-coronavirus spike glycoprotein. Emerg Microbes Infect 2019; 8: 516-30.

113 Lee SM, Kang WS, Cho AR, Kim T, Park JK. Psychological impact of the 2015 MERS outbreak on hospital workers and quarantined hemodialysis patients. Compr Psychiatry 2018; 87: 123-27.

114 Ahmed AE. The predictors of 3- and 30-day mortality in 660 MERS-CoV patients. BMC Infect Dis 2017; 17: 615.

115 Park JE, Jung S, Kim A, Park JE. MERS transmission and risk factors: a systematic review. BMC Public Health 2018; 18: 574.

116 Rahman A, Sarkar A. Risk factors for fatal Middle East respiratory syndrome coronavirus infections in Saudi Arabia: analysis of the WHO line list, 2013-2018. Am J Public Health 2019; 109: 1288-93.

117 Sha J, Li Y, Chen X, et al. Fatality risks for nosocomial outbreaks of Middle East respiratory syndrome coronavirus in the Middle East and South Korea. Arch Virol 2017; 162: 33-44.

118 Seys LJM, Widagdo W, Verhamme FM, et al. DPP4, the Middle East respiratory syndrome coronavirus receptor, is upregulated in lungs of smokers and chronic obstructive pulmonary disease patients. Clin Infect Dis 2018; 66: 45-53.

119 Batawi S, Tarazan N, Al-Raddadi R, et al. Quality of life reported by survivors after hospitalization for Middle East respiratory syndrome (MERS). Health Qual Life Outcomes 2019; 17: 101.

120 Ngai JC, Ko FW, Ng SS, To KW, Tong M, Hui DS. The long-term impact of severe acute respiratory syndrome on pulmonary function, exercise capacity and health status. Respirology 2010; 15: $543-50$

121 WHO. WHO target product profiles for MERS-CoV vaccines. 2017. https://www.who.int/blueprint/what/research-development/ MERS_CoV_TPP_15052017.pdf?ua=1\&ua=1 (accessed Aug 30, 2019).

122 Schindewolf C, Menachery VD. Middle East respiratory syndrome vaccine candidates: cautious optimism. Viruses 2019; 11: e74

123 Hemida MG. Middle East respiratory syndrome coronavirus and the One Health concept. PeerJ 2019; 7: e7556.
124 Hemida MG, Alnaeem A. Some one health based control strategies for the Middle East respiratory syndrome coronavirus. One Health 2019; 8: 100102

125 Park S, Park JY, Song Y, How SH, Jung KS. Emerging respiratory infections threatening public health in the Asia-Pacific region: a position paper of the Asian Pacific society of respirology. Respirology 2019; 24: 590-97.

126 Zumla A, Dar O, Kock R, et al. Taking forward a 'one health' approach for turning the tide against the Middle East respiratory syndrome coronavirus and other zoonotic pathogens with epidemic potential. Int J Infect Dis 2016; 47: 5-9.

127 Kirchdoerfer RN, Ward AB. Structure of the SARS-CoV nsp12 polymerase bound to nsp7 and nsp8 co-factors. Nat Commun 2019; 10: 2342

128 Chu DKW, Hui KPY, Perera R, et al. MERS coronaviruses from camels in Africa exhibit region-dependent genetic diversity. Proc Natl Acad Sci USA 2018; 115: 3144-49.

129 Lamers MM, Raj VS, Shafei M, et al. Deletion variants of Middle East respiratory syndrome coronavirus from humans, Jordan, 2015. Emerg Infect Dis 2016; 22: 716-19.

130 Xie Q, Cao Y, Su J, et al. Two deletion variants of Middle East respiratory syndrome coronavirus found in a patient with characteristic symptoms. Arch Virol 2017; 162: 2445-49.

131 Knoops K, Kikkert M, Worm SH, et al. SARS-coronavirus replication is supported by a reticulovesicular network of modified endoplasmic reticulum. PLoS Biol 2008; 6: e226.

132 Amer H, Alqahtani AS, Alaklobi F, Altayeb J, Memish ZA. Healthcare worker exposure to Middle East respiratory syndrome coronavirus (MERS-CoV): revision of screening strategies urgently needed. Int J Infect Dis 2018; 71: 113-16.

133 Al-Abdallat MM, Payne DC, Alqasrawi S, et al. Hospital-associated outbreak of Middle East respiratory syndrome coronavirus: a serologic, epidemiologic, and clinical description. Clin Infect Dis 2014; 59: 1225-33.

134 Alenazi TH, Al Arbash H, El-Saed A, et al. Identified transmission dynamics of Middle East respiratory syndrome coronavirus infection during an outbreak: implications of an overcrowded emergency department. Clin Infect Dis 2017; 65: 675-79.

135 Hui DS, Peiris M. Middle East respiratory syndrome. Am J Respir Crit Care Med 2015; 192: 278-79.

136 Nam HS, Park JW, Ki M, Yeon MY, Kim J, Kim SW. High fatality rates and associated factors in two hospital outbreaks of MERS in Daejeon, the Republic of Korea. Int J Infect Dis 2017; 58: 37-42.

137 Oboho IK, Tomczyk SM, Al-Asmari AM, et al. 2014 MERS-CoV outbreak in Jeddah—a link to health care facilities. $N$ Engl J Med 2015; 372: 846-54.

138 Hunter JC, Nguyen D, Aden B, et al. Transmission of Middle East respiratory syndrome coronavirus infections in healthcare settings, Abu Dhabi. Emerg Infect Dis 2016; 22: 647-56.

139 Jo S, Kim H, Kim S, Shin DH, Kim MS. Characteristics of flavonoids as potent MERS-CoV 3c-like protease inhibitors Chem Biol Drug Des 2019; 94: 2023-30.

140 Mustafa S, Balkhy H, Gabere MN. Current treatment options and the role of peptides as potential therapeutic components for Middle East respiratory syndrome (MERS): a review. J Infect Public Health 2018; 11: 9-17.

141 Agostini ML, Pruijssers AJ, Chappell JD, et al. Small-molecule antiviral beta-d- $\mathrm{n}^{4}$-hydroxycytidine inhibits a proofreading-intact coronavirus with a high genetic barrier to resistance. J Virol 2019; 93: e01348-19.

142 Sheahan TP, Sims AC, Graham RL, et al. Broad-spectrum antiviral GS-5734 inhibits both epidemic and zoonotic coronaviruses. Sci Transl Med 2017; 9: eaal3653.

143 Taylor R, Kotian P, Warren T, et al. BCX4430 — a broad-spectrum antiviral adenosine nucleoside analog under development for the treatment of Ebola virus disease. J Infect Public Health 2016; 9: 220-26.

(C) 2020 Elsevier Ltd. All rights reserved. 